\title{
Inhibition of swarming and virulence factor expression in Proteus mirabilis by resveratrol
}

\author{
Correspondence \\ Shwu-Jen Liaw \\ s-jliaw@ha.mc.ntu.edu.tw
}

Received 4 April 2006

Accepted 3 July 2006

\author{
Won-Bo Wang, ${ }^{1}$ Hsin-Chih Lai, ${ }^{2,3}$ Po-Ren Hsueh, ${ }^{3}$ Robin Y.-Y. Chiou, ${ }^{4}$ \\ Shwu-Bin Lin ${ }^{2,3}$ and Shwu-Jen Liaw ${ }^{2,3}$ \\ ${ }^{1,2}$ Graduate Institute of Microbiology ${ }^{1}$ and Department and Graduate Institute of Clinical \\ Laboratory Sciences and Medical Biotechnology2, College of Medicine, National Taiwan \\ University, 10016 no. 1 Chang-Te Street, Taipei, Taiwan, Republic of China \\ ${ }^{3}$ Department of Laboratory Medicine, National Taiwan University Hospital, Taipei, Taiwan, \\ Republic of China \\ ${ }^{4}$ Department of Food Science, National Chiayi University, Chiayi, Taiwan, Republic of China
}

\section{INTRODUCTION}

Proteus mirabilis, a motile Gram-negative enteric bacterium, is an important pathogen of the urinary tract, and is the primary infectious agent in patients with indwelling urinary catheters (Warren et al., 1982). Individuals suffering from urinary tract infections caused by P. mirabilis often develop bacteriuria, cystitis, kidney and bladder stones, catheter obstruction due to stone encrustation, acute pyelonephritis, and fever (Burall et al., 2004; Johnson et al., 1993; Mobley \& Warren, 1987).

The ability of $P$. mirabilis to colonize the surfaces of catheters and the urinary tract is believed to be aided by a characteristic known as swarming differentiation and migration (Allison et al., 1994). P. mirabilis swarming involves the coordinate differentiation of short, motile, vegetative cells with a few peritrichous flagella into multinucleate, aseptate swarm cells of up to 40 times the vegetative cell length, and with more than a 50-fold greater surface density of flagella. The swarm cells migrate coordinately and rapidly away from the colony as multicellular rafts until they pause (consolidation) and

Abbreviations: OS, quorum sensing; resveratrol, 3,5,4-trihydroxy-transstilbene; ROS, reactive oxygen species. undergo some de-differentiation (Allison \& Hughes, 1991b; Rauprich et al., 1996). Regular cycles of migration and consolidation generate a colony on the agar surface with a characteristic pattern of concentric rings (Allison \& Hughes, 1991b; Rauprich et al., 1996).

Several potential virulence factors may be responsible for the pathogenicity of $P$. mirabilis. Among them, flagella, necessary for motility, are involved in establishing infection (Harmon et al., 1989). Urease, which is responsible for the formation of bladder and kidney stones at later stages of infection (Mobley \& Hausinger, 1989), can facilitate the colonization of the urinary tract in a mouse model (Jones et al., 1990). Haemolysin, which is cytotoxic for cultured urinary tract epithelial cells (Mobley et al., 1991), has been shown to be correlated with the ability of bacteria to invade cells (Peerbooms et al., 1984). The ability of P. mirabilis to express virulence factors, including urease and haemolysin, and to invade human urothelial cells, is coordinately regulated with swarming differentiation (Allison \& Hughes, 1991a; Allison et al., 1992b; Liaw et al., 2000, 2001, 2004). Characterization of Proteus mutants has indicated that a substantial number of proteins, including FlhD $\mathrm{C}_{2}$, FlhA, Umo, Lrp, RsbA, RsmA, SpeB and others, are involved in regulation of swarming and virulence factor 
expression (Dufour et al., 1998; Fraser \& Hughes, 1999; Gygi et al., 1995a; Hay et al., 1997). Among these regulatory proteins, RsbA, which has been suggested to be a Hiscontaining phosphotransmitter of the bacterial two-component signalling system (Belas et al., 1998; Liaw et al., 2001; Takeda et al., 2001), has been shown by us to act as a negative regulator of swarming differentiation and virulence factor expression in P. mirabilis (Liaw et al., 2001, 2004).

Resveratrol (3,5,4-trihydroxy-trans-stilbene) is a naturally occurring phytoalexin, one of a group of compounds that are produced in plants during the stress of attack by pathogens (Dong, 2003; Jeandet et al., 2002). Invasion of grapevines by fungi induces the production of resveratrol to ward off the damaging microbes (Jeandet et al., 2002). The compound is found in some foods and drinks, including red wine, grapes and peanuts. Resveratrol has been shown to have anti-inflammatory, anti-proliferative, antiviral and antioxidant activities (Jeandet et al., 2002). Intensive research has been directed to the role of resveratrol in human health, primarily because of its protective effects against cardiac ailments and cancer (Jeandet et al., 2002). Recent studies have indicated that resveratrol has growthinhibitory effects on some bacterial pathogens (Chan, 2002; Docherty et al., 2001; Mahady \& Pendland, 2000; Tegos et al., 2002). In the course of studying the effect of resveratrol on human pathogens, we found that resveratrol could inhibit swarming and virulence factor expression in P. mirabilis. This finding suggests that resveratrol has the potential to be developed as an antimicrobial agent against $P$. mirabilis.

\section{METHODS}

Chemicals. All chemicals were purchased from Sigma.

Bacterial strains and growth conditions. The bacterial strains used in this study were the wild-type $P$. mirabilis $\mathrm{P} 19$, a $P$. mirabilis P19 rsbA-defective mutant (P1100), and a RsbA-complemented strain (Pc) (Liaw et al., 2001, 2004). Bacteria were routinely cultured at $37^{\circ} \mathrm{C}$ in Luria-Bertani (LB) medium.

Swarming behaviour assay. The swarming migration distance assay was performed as described previously (Gygi et al., 1995b; Liaw et al., 2001). Briefly, an overnight bacterial culture (5 $\mu \mathrm{l})$ was inoculated centrally onto the surface of dry LB swarming agar $(2 \%$, $\mathrm{w} / \mathrm{v})$ plates with or without resveratrol, which were then incubated at $37^{\circ} \mathrm{C}$. The swarming migration distance was assayed by following swarm fronts of the bacterial cells and recording progress at 30 or 60 min intervals.

Measurement of cell length, haemolysin and urease activities, and flagellin level. Cell length, cell membrane-associated haemolysin activity, urease activity in whole-cell suspensions, and flagellin, were assayed as described previously (Liaw et al., 2001, 2004).

Cell invasion assay. Wild-type or $r s b A$-defective $P$. mirabilis grown overnight in the presence or absence of resveratrol $\left(30 \mu \mathrm{g} \mathrm{ml}^{-1}\right)$ were used to infect a human urothelial NTUB1 cell line, which was originally derived from a urinary bladder carcinoma, and was obtained from the National Taiwan University Hospital. The cell-invasion ability of the bacteria was then assayed as described previously (Liaw et al., 2000, 2001).

\section{RESULTS}

\section{Inhibition of $\boldsymbol{P}$. mirabilis swarming by resveratrol}

To test the effect of resveratrol on $P$. mirabilis swarming, the bacteria were inoculated onto the centre of LB swarming agar plates containing various concentrations of resveratrol, and the migration distance of the bacteria was measured. Resveratrol significantly inhibited swarming migration of $P$. mirabilis at concentrations as low as $15 \mu \mathrm{g} \mathrm{ml}^{-1}$ (Fig. 1b, lower panel); swarming was inhibited in a dose-dependent manner. At a concentration of $60 \mu \mathrm{g} \mathrm{ml}^{-1}$, resveratrol completely blocked the swarming ability of $P$. mirabilis (Fig. 1a, b). Previously, we have reported that $r s b A$-defective $P$. mirabilis mutants have a higher ability to swarm and to express virulence factors, and have suggested that RsbA acts as a repressor of swarming and virulence factor expression (Liaw et al., 2001). To investigate whether RsbA plays a role in resveratrol-induced swarming inhibition, an $r s b A$ defective mutant, P1100, was tested for its response to resveratrol. Consistent with our previous report (Liaw et al., 2001), the $r s b A$-defective mutant migrated further in a given time than the wild-type cells. Whereas swarming of wildtype $P$. mirabilis was inhibited by resveratrol, that of the $r s b A$-defective mutant was not (Fig. 1a, b). These data indicate that resveratrol inhibited $P$. mirabilis swarming through an RsbA-dependent pathway. The inhibitory effect of resveratrol on swarming might arise from a toxic effect on the bacteria. We therefore tested whether resveratrol affected the growth rate of $P$. mirabilis. As shown in Fig. 1(c), the growth rate of both wild-type and $r s b A$ defective $P$. mirabilis was inhibited slightly by resveratrol at 30 and $60 \mu \mathrm{g} \mathrm{ml}^{-1}$. At $16 \mathrm{~h}$ post-inoculation, the bacteria grew to similar densities, regardless of the presence of resveratrol. Considering the fact that resveratrol could inhibit swarming but only marginally inhibit growth in wild-type P. mirabilis, and that resveratrol slightly inhibited growth but not swarming in mutant $P$. mirabilis, we concluded that the inhibitory effect of resveratrol on swarming was unlikely to be due to inhibition of cell growth.

\section{Inhibition of swarming differentiation of P. mirabilis by resveratrol}

Knowing that the swarming behaviour of $P$. mirabilis was inhibited by resveratrol, experiments were performed to determine whether swarming differentiation of $P$. mirabilis was also affected by resveratrol. Wild-type and $r s b A$ defective mutant cells were spread on LB swarming agar plates in the presence or absence of resveratrol. Cell length, a marker of cell differentiation, was measured $2 \mathrm{~h}$ after seeding and hourly thereafter. As shown in Fig. 2(a), in the absence of resveratrol, the $r s b A$-defective mutant formed longer cells than the wild-type strain during the $7 \mathrm{~h}$ incubation period, and became longest about $1 \mathrm{~h}$ earlier than wild-type cells. Moreover, the $r s b A$-defective mutant retained its elongated cell shape for longer than the wildtype strain. These data, consistent with our previous report 
(a)

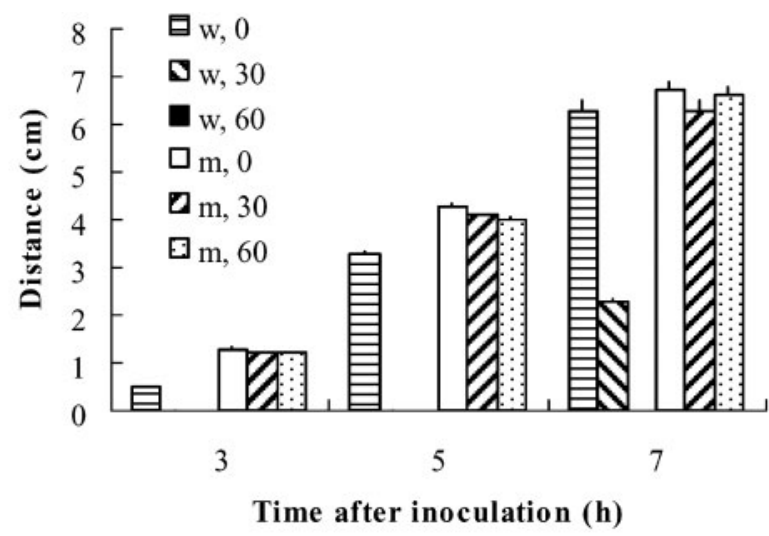

(b)

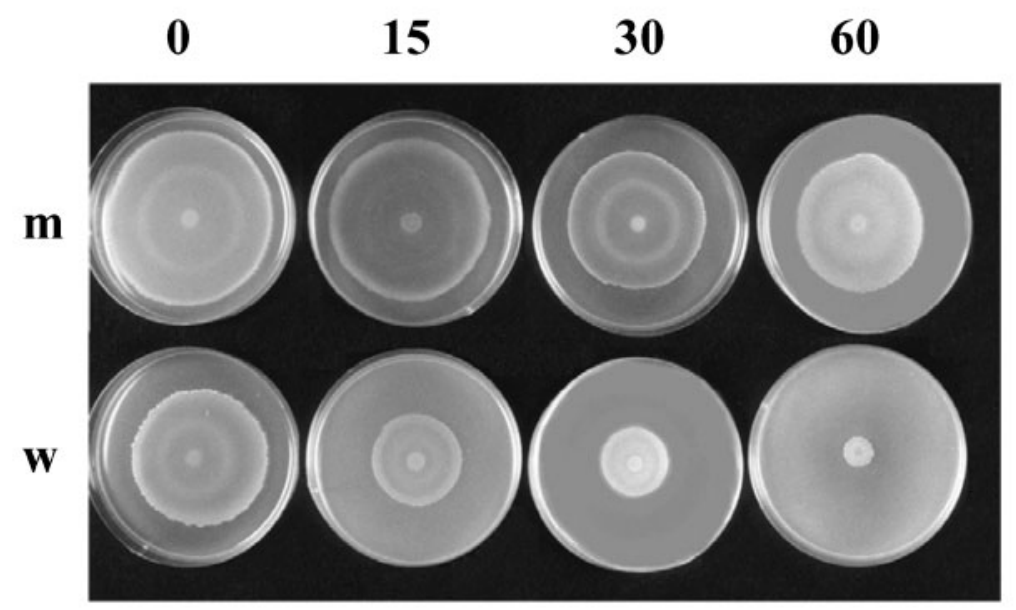

(c)

Wild-type
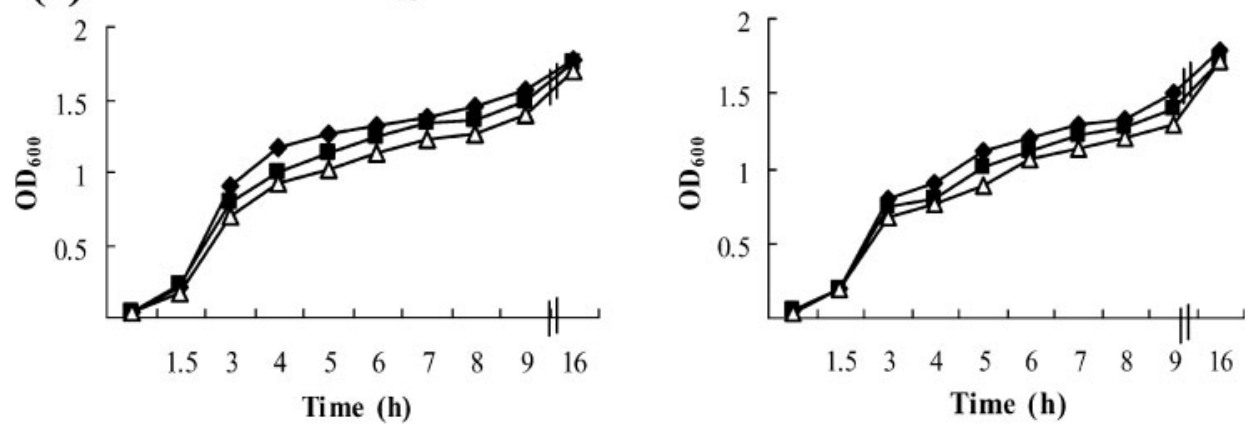

Fig. 1. (a) Effect of resveratrol on the swarming of wild-type and $r s b A$-defective $P$. mirabilis. The histogram shows the swarming migration distance of wild-type and $r s b A$-defective $P$. mirabilis in the presence of various concentrations of resveratrol $\left(0,30\right.$ or $\left.60 \mu \mathrm{g} \mathrm{m}^{-1}\right)$. The data represent the mean and SD of four independent experiments. w, wild-type; $\mathrm{m}$, $r s b A$-defective mutant. (b) Halo images of swarming plates containing different concentrations of resveratrol $(0,15,30$ or $60 \mu \mathrm{g} \mathrm{ml}^{-1}$ ) at $8 \mathrm{~h}$ after inoculation. (c) Effect of resveratrol on the growth of wild-type and rsbA-defective $P$. mirabilis. Overnight bacterial culture was diluted $1: 100$ to fresh LB broth containing different concentrations of resveratrol: $0 \mu \mathrm{g} \mathrm{ml}^{-1}$ $(\Delta), 30 \mu \mathrm{g} \mathrm{ml}^{-1}(\boldsymbol{\square})$ or $60 \mu \mathrm{g} \mathrm{ml}^{-1}(\triangle)$. The bacterial growth was monitored thereafter as $\mathrm{OD}_{600}$. Data are the mean of three determinations.

(Liaw et al., 2001), indicate that the $r s b A$-defective mutant differentiated earlier and maintained a differentiated state for longer than the wild-type strain.
When resveratrol was added to the LB swarming agar plates, the length of the wild-type cells was reduced, but that of the $r s b A$-defective mutant cells was not (Fig. 2a, b). These data 
(a)

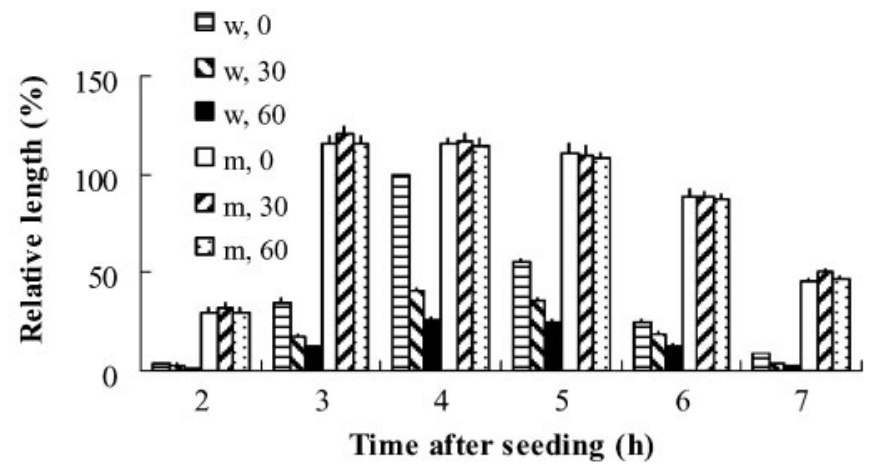

(b)
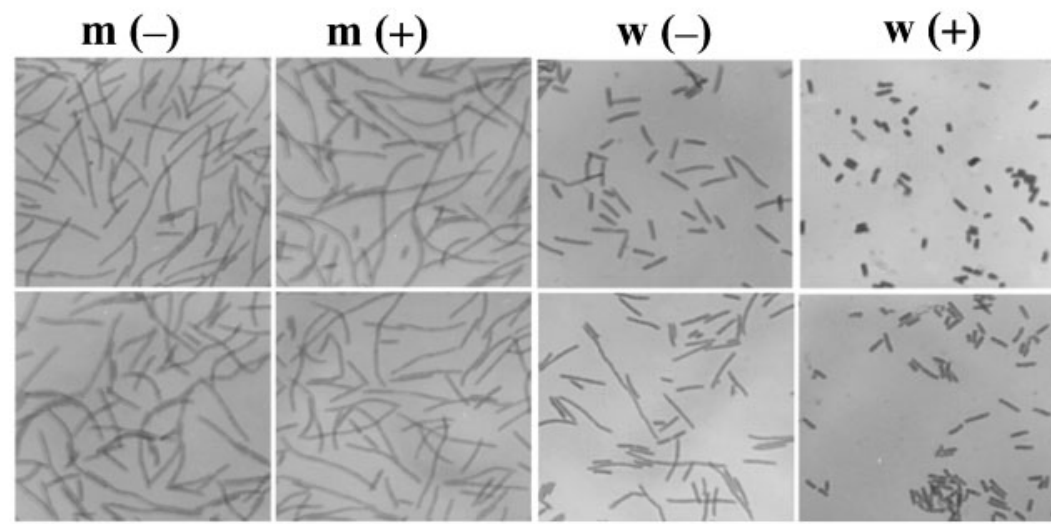

(c)

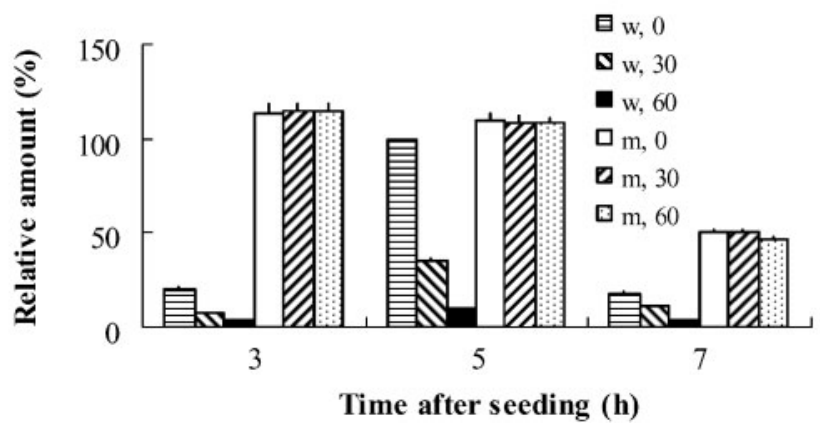

Fig. 2. (a) Effect of resveratrol on the cell length of wild-type and $r s b A$-defective $P$. mirabilis. The histogram shows the relative cell length of the wild-type $P$. mirabilis and its $r s b A$ mutant in different concentrations of resveratrol $(0,30$ or $60 \mu \mathrm{g} \mathrm{ml}^{-1}$ ). The values obtained with wild-type cells in the absence of resveratrol at $4 \mathrm{~h}$ post-seeding were set at $100 \%$, and all other values were expressed relative to this value. The data represent the means of three independent experiments. $\mathrm{w}$, wild-type; $\mathrm{m}, r s b A$-defective mutant. (b) Microscopic observation of wild-type and $r s b A$-defective $P$. mirabilis in the presence or absence of resveratrol at 3 and $5 \mathrm{~h}$ post-seeding. - , No resveratrol;,$+ 60 \mu \mathrm{g}$ resveratrol $\mathrm{ml}^{-1}$. (c) Effect of resveratrol on flagellin production by wild-type and $r s b A$-defective $P$. mirabilis. The amount of flagellin produced by the wild-type cells in the absence of resveratrol at $5 \mathrm{~h}$ post-seeding was set at $100 \%$. The data represent the means of three independent experiments.

indicate that resveratrol inhibited swarming differentiation of $P$. mirabilis and that this inhibition was mediated through an RsbA-dependent pathway.

This conclusion was also confirmed by the finding that resveratrol could inhibit flagellin production in wild-type, but not in mutant, P. mirabilis (Fig. 2c).

\section{Inhibition of virulence factor expression in $P$. mirabilis by resveratrol}

In P. mirabilis, expression of virulence factors is regulated by RsbA coordinately with swarming differentiation (Liaw et al., 2001). We next tested whether expression of virulence factors, including haemolysin and urease, was also affected 
by resveratrol in $P$. mirabilis. As shown in Fig. 3 , in the absence of resveratrol, the $r s b A$-defective mutant expressed higher levels of haemolysin and urease activity than the wildtype strain during the $7 \mathrm{~h}$ incubation period, consistent with our previous report (Liaw et al., 2001). Resveratrol inhibited the haemolysin and urease activity of wild-type $P$. mirabilis, but not that of the $r s b A$-defective mutant, indicating that resveratrol could inhibit the expression of haemolysin and urease in P. mirabilis through an RsbA-dependent pathway.

\section{Inhibition of the cell-invasion ability of $P$. mirabilis by resveratrol}

Swarming differentiation and expression of virulence factors are correlated with the ability of $P$. mirabilis to invade cells (Allison et al., 1992a, b). Knowing that swarming differentiation and virulence factor expression were inhibited by resveratrol, we next tested whether resveratrol could
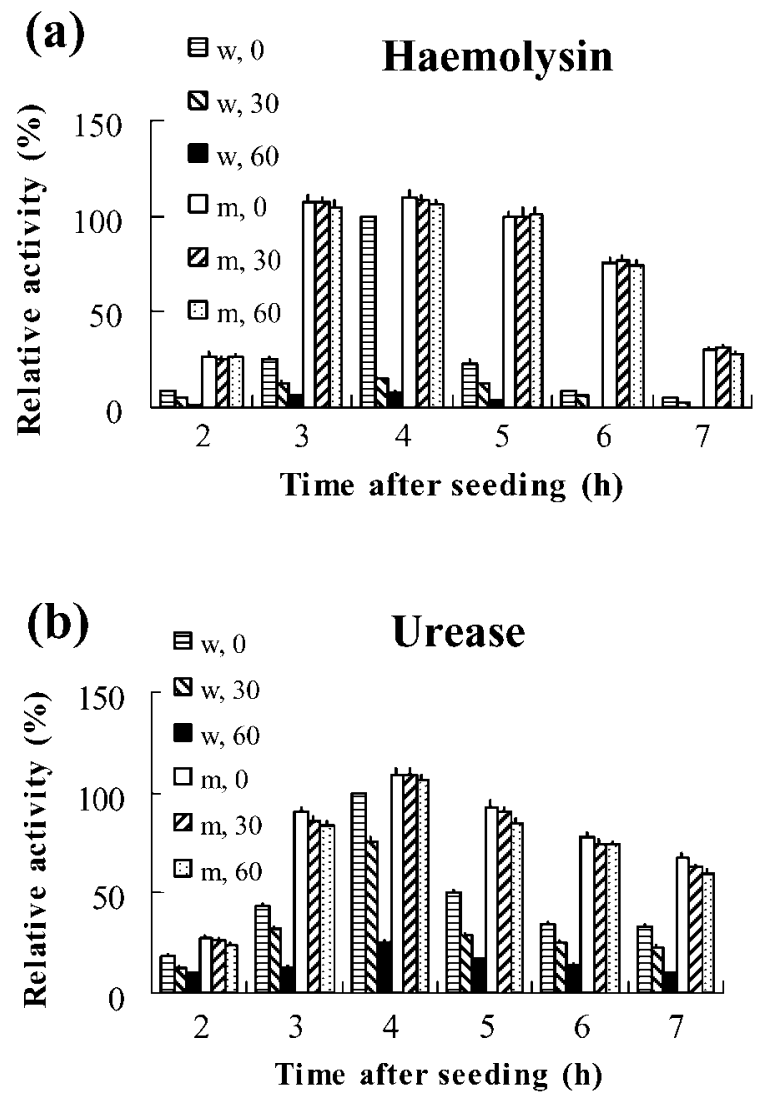

Fig. 3. Effect of resveratrol on the haemolysin activity (a) and urease activity (b) of wild-type and $r s b A$-defective $P$. mirabilis. The histogram shows the relative haemolysin or urease activity of the wild-type $P$. mirabilis and its $r s b A$ mutant at different concentrations of resveratrol $\left(0,30\right.$ or $\left.60 \mu \mathrm{g} \mathrm{ml}^{-1}\right)$. The values obtained with wild-type cells in the absence of resveratrol at $4 \mathrm{~h}$ post-seeding were set at $100 \%$, and all other values were expressed relative to this value. The data represent the means of three independent experiments. $\mathrm{w}$, wild-type; $\mathrm{m}, r s b A$-defective mutant. inhibit the cell-invasion ability of wild-type and $r s b A$ defective $P$. mirabilis. As shown in Table 1, the $r s b A$ defective mutant exhibited higher cell-invasion ability than wild-type cells, consistent with our previous report (Liaw et al., 2001). Resveratrol inhibited the cell-invasion ability of wild-type $P$. mirabilis, but not that of the $r s b A$-defective mutant, indicating that resveratrol could inhibit the cellinvasion ability of $P$. mirabilis through an RsbA-dependent pathway.

\section{Complementation of the rsbA-defective mutant by wild-type rsbA restores wild-type responsiveness to resveratrol}

To further confirm that loss of responsiveness to resveratrol in the $r s b A$-defective mutant is indeed due to the defective $r s b A$ gene, an RsbA-complemented strain $(\mathrm{Pc})$, which was generated by transforming the wild-type $r s b A$ gene into the rsbA-defective mutant (Liaw et al., 2001), was tested for its responsiveness to resveratrol. As shown in Fig. 4(a), in the absence of resveratrol, while the $r s b A$-defective mutant exhibited the superswarming phenotype, the RsbA-complemented strain exhibited swarming behaviour similar to that of wild-type P. mirabilis. In the presence of resveratrol, swarming of the $r s b A$-defective mutant was not inhibited, but that of the RsbA-complemented strain was inhibited to a level similar to that of the wild-type strain. Together, these data indicate that expression of RsbA in the $r s b A$-defective mutant led to the restoration of responsiveness to resveratrol, and suggest that inhibition of swarming by resveratrol is mediated through RsbA and not through other proteins in P. mirabilis. We also tested whether resveratrol could inhibit haemolysin expression in the RsbA-complemented strain as it could in the wild-type strain. As shown in Fig. 4(b), while the haemolysin activity of the $r s b A$-defective mutant was not inhibited by resveratrol, the activity of the RsbA-complemented strain was inhibited to a level similar to that of the wild-type strain. These data further confirm that complementation of the $r s b A$-defective mutant with the $r s b A$ gene restored its responsiveness to resveratrol, and that inhibition of haemolysin expression by resveratrol was mediated mainly through RsbA in P. mirabilis.

Table 1. Effect of resveratrol on the cell-invasion ability of $P$. mirabilis strains

\begin{tabular}{|lc|}
\hline Strain & Cell invasion $(\%)^{\star}$ \\
\hline Wild-type & $0 \cdot 09 \pm 0 \cdot 01$ \\
Mutant $\dagger$ & $0 \cdot 21 \pm 0 \cdot 013$ \\
Wild-type $+\mathrm{RV} \ddagger$ & $0 \cdot 02 \pm 0 \cdot 01$ \\
Mutant $+\mathrm{RV}$ & $0 \cdot 21 \pm 0 \cdot 012$ \\
\hline
\end{tabular}

${ }^{\star}$ Values represent the mean \pm SD of three experiments.

$\dagger$ Mutant, $r s b A$-defective mutant.

$\ddagger \mathrm{RV}, 30 \mu \mathrm{g}$ resveratrol $\mathrm{ml}^{-1}$. 


\section{(a)}
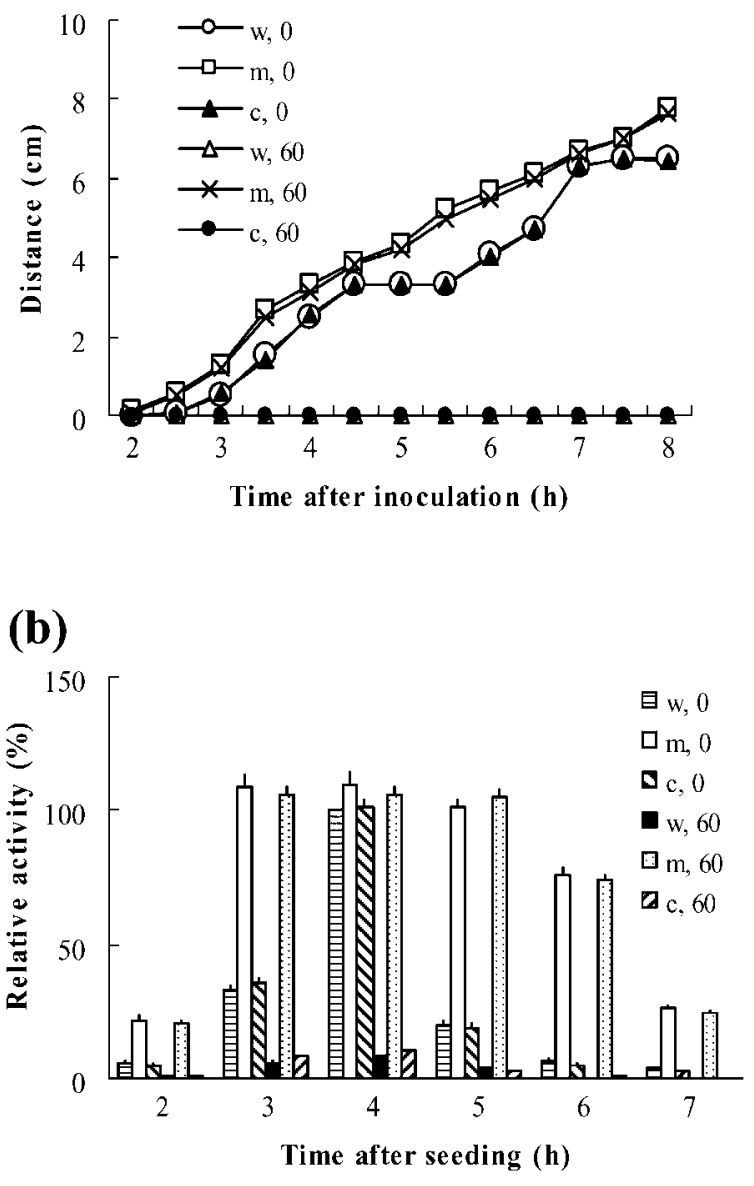

Fig. 4. Complementation of the $r s b A$-defective mutant of $P$. mirabilis by the wild-type $r s b A$ gene restored wild-type responsiveness to resveratrol. The swarming migration distance (a) and the haemolysin activity (b) of different strains of $P$. mirabilis in the presence or absence of $60 \mu \mathrm{g}$ resveratrol $\mathrm{ml}^{-1}$ at various times after inoculation were determined. For haemolysin activity measurements, the value obtained with the wild-type cells in the absence of resveratrol at $4 \mathrm{~h}$ post-seeding was set at $100 \%$. The data represent the means of three independent experiments. $\mathrm{w}$, wild-type; $\mathrm{m}, \mathrm{rsbA}$-defective mutant; c, RsbAcomplemented strain.

\section{DISCUSSION}

A wide variety of natural products has been under scrutiny for their clinical potential, both in terms of disease prevention and treatment. Here we report that resveratrol, a naturally occurring phytoalexin, can inhibit swarming and the expression of virulence factors in $P$. mirabilis. To our knowledge, this is the first report describing the inhibitory effect of resveratrol on bacterial swarming and virulence factor expression.

Resveratrol inhibits the growth of some bacterial species, but has little effect on others (Docherty et al., 2001; Mahady \& Pendland, 2000; Tegos et al., 2002). Several lines of evidence indicate that the inhibitory effect of resveratrol on $P$. mirabilis swarming and virulence factor expression is unlikely to be due to its inhibitory effect on bacterial growth. Firstly, resveratrol inhibited $P$. mirabilis swarming and virulence factor expression at a concentration as low as $30 \mu \mathrm{g} \mathrm{ml}^{-1}$ (Figs 1 and 3), but did not significantly affect the growth rate of the bacteria at concentrations up to $60 \mu \mathrm{g} \mathrm{ml}^{-1}$ (Fig. 1c). Secondly, resveratrol did not affect the viability of $P$. mirabilis at a concentration of $256 \mu \mathrm{g} \mathrm{ml} l^{-1}$ (data not shown). Thirdly, while resveratrol could slightly inhibit the growth rate of both wild-type and $r s b A$-defective $P$. mirabilis, it could only inhibit swarming and virulence factor expression in the wild-type strain, and not in the mutant strain of P. mirabilis (Figs 1 and 3).

If resveratrol is to be used to treat or prevent $P$. mirabilis infection, its effect on human cells needs to be addressed. Our study showed that resveratrol inhibited $P$. mirabilis swarming and virulence factor expression at 30-60 $\mu \mathrm{g} \mathrm{ml}^{-1}$. At this concentration, resveratrol is expected to have little effect on normal human cells. For instance, the midpoint cytotoxicity values for a $24 \mathrm{~h}$ exposure to resveratrol are 98.6-105.4 $\mu \mathrm{g} \mathrm{ml}^{-1}$ for normal fibroblasts isolated from the oral cavity (Babich et al., 2000). Our study also indicated that human embryonal rhabdomyosarcoma cells treated with $30 \mu \mathrm{g}$ resveratrol ml ${ }^{-1}$ for 3 days did not show signs of cell death (data not shown).

Quorum sensing (QS) is a cell to cell communication mechanism that enables bacteria to monitor their own population density and synchronize the expression of virulence factors, and thus to mount effective attacks to overwhelm the host's defence responses (Camara et al., 2002; de Kievit \& Iglewski, 2000; Zhang, 2003). Although the regulation of virulence factor expression by QS is generally believed to be dependent on cell density, there is increasing evidence to suggest that the cell-to-cell signalling mediated by the QS system can also be strongly affected by environmental factors other than cell density. For example, bioluminescence, which is regulated by QS in Vibrio harveyi, has been found to be sensitive to the availability of iron, oxygen and carbohydrate (Nealson \& Hastings, 1991). P. mirabilis swarming and virulence factor expression are generally believed to be regulated through a QS system (Holden et al., 1999; Schneider et al., 2002), and require the sensing and integration of a variety of environmental, cellto-cell and intracellular signals. These signals may include those transmitted by high population density, autoinducer2 (AI-2), cyclic dipeptides, putrescine, glutamine, intracellular cations and fatty acids (Allison et al., 1993; Holden et al., 1999; Lai et al., 1998; Liaw et al., 2004; Rather, 2005; Schneider et al., 2002; Sturgill \& Rather, 2004). Recently, oxidative stress has been found to upregulate the expression of QS-controlled genes in Pseudomonas aeruginosa (Juhas et al., 2004; Kim et al., 2005). It is possible that oxidative stress also serves as an environmental signal to regulate QS in $P$. mirabilis. We propose that oxidative stress, as in $P$ s. aeruginosa, may also upregulate QS-regulated genes in $P$. 
mirabilis. Resveratrol, a powerful antioxidant, may relieve oxidative stress, and thus lead to the inhibition of swarming and virulence factor expression. This proposition is supported by our preliminary results that soy-derived isoflavones, also potent antioxidants, can inhibit swarming, but not growth, in P. mirabilis (data not shown).

The hypothesis that oxidative stress regulates $P$. mirabilis swarming is attractive, because it can explain the phenomenon by which swarming differentiation and virulence factor expression are dependent on cell density. Reactive oxygen species (ROS) are known to be generated physiologically during normal cell metabolism, and high cell density may lead to the accumulation of excessive ROS. At this stage, $P$. mirabilis starts to differentiate and migrate. As cells move out in swarming rafts, the concentration of ROS decreases, and eventually cells are unable to maintain the differentiated state and de-differentiate back to non-motile vegetative cells. During growth, ROS build up again, and differentiation/swarming proceeds for a second cycle. Regular cycles of differentiation/migration and de-differentiation/non-migration generate a colony on the agar surface with a characteristic pattern of concentric rings. That oxidative stress may cause bacteria to migrate has been reported previously (Nachin et al., 2005; Tang et al., 2004). It is also of interest to note that bacterial infections of the genital tract can lead to the production of excess ROS from neutrophils/macrophages as a first-line defence mechanism (Ochsendorf, 1999). P. mirabilis may sense this increase in ROS and migrate away from the attack by immune cells.

RsbA, a His-containing phosphotransmitter of the bacterial two-component signalling system (Belas et al., 1998; Liaw et al., 2001; Takeda et al., 2001), has previously been shown by us to act as a negative regulator of swarming differentiation and virulence factor expression in $P$. mirabilis (Liaw et al., 2001, 2004). Here, we have shown that resveratrol inhibits $P$. mirabilis swarming and virulence factor expression through an RsbA-dependent pathway. At least two models can explain the role of RsbA in resveratrol-mediated suppression of swarming and virulence factor expression. First, P. mirabilis may contain a two-component membrane sensor kinase which can sense the low-ROS condition that results from resveratrol treatment. Upon sensing low ROS, this kinase may transduce negative signals via the phosphotransmitter RsbA to inhibit swarming and virulence factor expression. Alternatively, P. mirabilis may contain a twocomponent sensor kinase which can sense the high-ROS condition and transduce signals to down-regulate the expression of RsbA, a negative regulator of swarming and virulence factor expression in $P$. mirabilis. Upon resveratrol treatment (which results in low ROS), the presumed sensor kinase can no longer transduce signals to inhibit RsbA expression, leading to accumulation of RsbA, and inhibition of swarming and virulence factor expression. To distinguish these two possibilities, we measured the expression of RsbA upon resveratrol treatment. Our preliminary data indicated that the production of RsbA mRNA in P. mirabilis was increased six- to sevenfold after resveratrol treatment. This result is more consistent with the second model.

Another possible mechanism by which resveratrol could inhibit $P$. mirabilis swarming and virulence factor expression is by acting as a QS signal mimic that disrupts the bacterial QS system. There is increasing evidence to suggest that plants can produce a variety of signal mimics that inhibit QSregulated behaviours (Bauer \& Robinson, 2002; Teplitski et al., 2000). For example, the halogenated furanones produced by the seaweed Delisea pulchra can specifically inhibit QS-regulated biological activities in various Gramnegative bacteria (Givskov et al., 1996; Hentzer et al., 2002; Teplitski et al., 2000; Zhang, 2003). The crude exudates from pea (Pisum sativum) and crown vetch (Coronilla varia) strongly inhibit the QS-regulated synthesis of violacein in Chromobacterium violaceum (Teplitski et al., 2000). That some plants can produce QS-inhibitory molecules after their long association with bacterial pathogens is not surprising, because in this way, hosts can evade the pathogenic effects of the bacteria. It is possible that resveratrol, a natural product of many plants (about 31 genera), also acts as a QS-inhibitory molecule to protect plants from bacterial infection. Since different bacterial species may use similar QS signals to communicate with each other, it is possible that resveratrol, although produced by plants, also acts on human pathogens to disrupt their QS systems.

The emergence of bacterial strains that exhibit resistance to various antibiotics poses a major threat to medicine and public health. As a consequence, there is renewed interest in antibacterial targets which, by attenuating virulence, disrupt the capacity of pathogenic bacteria to cause infection. In this context, the QS system is considered to be a potential therapeutic target, and the inhibition of QS may lead to control of infection.

In this paper, we demonstrate that resveratrol, an antioxidant found in some foods and drinks, has an inhibitory effect on $P$. mirabilis swarming and virulence factor expression. Although the molecular mechanisms underlying resveratrol inhibition of swarming and virulence factor expression are not clear, this finding opens up the opportunity to develop drugs that slow down $P$. mirabilis infection, allowing the host to gain valuable time to activate defence mechanisms, and to stop and eliminate pathogenic invaders.

\section{ACKNOWLEDGEMENTS}

This work was supported by grants from the National Science Council and the National Taiwan University Hospital, Taipei, Taiwan. We are grateful to Yeong-Shiau Pu for providing the NTUB1 cell line.

\section{REFERENCES}

Allison, C. \& Hughes, C. (1991a). Bacterial swarming: an example of prokaryotic differentiation and multicellular behaviour. Sci Prog 75, $403-422$. 
Allison, C. \& Hughes, C. (1991b). Closely linked genetic loci required for swarm cell differentiation and multicellular migration by Proteus mirabilis. Mol Microbiol 5, 1975-1982.

Allison, C., Coleman, N., Jones, P. L. \& Hughes, C. (1992a). Ability of Proteus mirabilis to invade human urothelial cells is coupled to motility and swarming differentiation. Infect Immun 60, 4740-4746.

Allison, C., Lai, H. C. \& Hughes, C. (1992b). Co-ordinate expression of virulence genes during swarm-cell differentiation and population migration of Proteus mirabilis. Mol Microbiol 6, 1583-1591.

Allison, C., Lai, H. C., Gygi, D. \& Hughes, C. (1993). Cell differentiation of Proteus mirabilis is initiated by glutamine, a specific chemoattractant for swarming cells. Mol Microbiol 8, 53-60.

Allison, C., Emody, L., Coleman, N. \& Hughes, C. (1994). The role of swarm cell differentiation and multicellular migration in the uropathogenicity of Proteus mirabilis. J Infect Dis 169, 1155-1158.

Babich, H., Reisbaum, A. G. \& Zuckerbraun, H. L. (2000). In vitro response of human gingival epithelial S-G cells to resveratrol. Toxicol Lett 114, 143-153.

Bauer, W. D. \& Robinson, J. B. (2002). Disruption of bacterial quorum sensing by other organisms. Curr Opin Biotechnol 13, 234-237.

Belas, R., Schneider, R. \& Melch, M. (1998). Characterization of Proteus mirabilis precocious swarming mutants: identification of $r s b A$, encoding a regulator of swarming behavior. J Bacteriol 180, 6126-6139.

Burall, L. S., Harro, J. M., Li, X., Lockatell, C. V., Himpsl, S. D., Hebel, J. R., Johnson, D. E. \& Mobley, H. L. (2004). Proteus mirabilis genes that contribute to pathogenesis of urinary tract infection: identification of 25 signature-tagged mutants attenuated at least 100-fold. Infect Immun 72, 2922-2938.

Camara, M., Williams, P. \& Hardman, A. (2002). Controlling infection by tuning in and turning down the volume of bacterial small-talk. Lancet Infect Dis 2, 667-676.

Chan, M. M. (2002). Antimicrobial effect of resveratrol on dermatophytes and bacterial pathogens of the skin. Biochem Pharmacol 63, 99-104.

de Kievit, T. R. \& Iglewski, B. H. (2000). Bacterial quorum sensing in pathogenic relationships. Infect Immun 68, 4839-4849.

Docherty, J. J., Fu, M. M. \& Tsai, M. (2001). Resveratrol selectively inhibits Neisseria gonorrhoeae and Neisseria meningitidis. J Antimicrob Chemother 47, 243-244.

Dong, Z. (2003). Molecular mechanism of the chemopreventive effect of resveratrol. Mutat Res 523-524, 145-150.

Dufour, A., Furness, R. B. \& Hughes, C. (1998). Novel genes that upregulate the Proteus mirabilis flhDC master operon controlling flagellar biogenesis and swarming. Mol Microbiol 29, 741-751.

Fraser, G. M. \& Hughes, C. (1999). Swarming motility. Curr Opin Microbiol 2, 630-635.

Givskov, M., de Nys, R., Manefield, M., Gram, L., Maximilien, R., Eberl, L., Molin, S., Steinberg, P. D. \& Kjelleberg, S. (1996). Eukaryotic interference with homoserine lactone-mediated prokaryotic signalling. J Bacteriol 178, 6618-6622.

Gygi, D., Bailey, M. J., Allison, C. \& Hughes, C. (1995a). Requirement for FlhA in flagella assembly and swarm-cell differentiation by Proteus mirabilis. Mol Microbiol 15, 761-769.

Gygi, D., Rahman, M. M., Lai, H. C., Carlson, R., Guard-Petter, J. \& Hughes, C. (1995b). A cell-surface polysaccharide that facilitates rapid population migration by differentiated swarm cells of Proteus mirabilis. Mol Microbiol 17, 1167-1175.

Harmon, R. C., Rutherford, R. L., Wu, H. M. \& Collins, M. S. (1989). Monoclonal antibody-mediated protection and neutralization of motility in experimental Proteus mirabilis infection. Infect Immun 57, 1936-1941.

Hay, N. A., Tipper, D. J., Gygi, D. \& Hughes, C. (1997). A nonswarming mutant of Proteus mirabilis lacks the Lrp global transcriptional regulator. J Bacteriol 179, 4741-4746.

Hentzer, M., Riedel, K., Rasmussen, T. B. \& 9 other authors (2002). Inhibition of quorum sensing in Pseudomonas aeruginosa biofilm bacteria by a halogenated furanone compound. Microbiology 148, $87-102$.

Holden, M. T., Ram Chhabra, S., de Nys, R. \& 14 other authors (1999). Quorum-sensing cross talk: isolation and chemical characterization of cyclic dipeptides from Pseudomonas aeruginosa and other Gram-negative bacteria. Mol Microbiol 33, 1254-1266.

Jeandet, P., Douillet-Breuil, A. C., Bessis, R., Debord, S., Sbaghi, M. \& Adrian, M. (2002). Phytoalexins from the Vitaceae: biosynthesis, phytoalexin gene expression in transgenic plants, antifungal activity, and metabolism. J Agric Food Chem 50, 2731-2741.

Johnson, D. E., Russell, R. G., Lockatell, C. V., Zulty, J. C., Warren, J. W. \& Mobley, H. L. (1993). Contribution of Proteus mirabilis urease to persistence, urolithiasis, and acute pyelonephritis in a mouse model of ascending urinary tract infection. Infect Immun $\mathbf{6 1}$ 2748-2754

Jones, B. D., Lockatell, C. V., Johnson, D. E., Warren, J. W. \& Mobley, H. L. (1990). Construction of a urease-negative mutant of Proteus mirabilis: analysis of virulence in a mouse model of ascending urinary tract infection. Infect Immun 58, 1120-1123.

Juhas, M., Wiehlmann, L., Huber, B. \& 8 other authors (2004). Global regulation of quorum sensing and virulence by VqsR in Pseudomonas aeruginosa. Microbiology 150, 831-841.

Kim, E. J., Wang, W., Deckwer, W. D. \& Zeng, A. P. (2005). Expression of the quorum-sensing regulatory protein LasR is strongly affected by iron and oxygen concentrations in cultures of Pseudomonas aeruginosa irrespective of cell density. Microbiology 151, $1127-1138$

Lai, H. C., Gygi, D., Fraser, G. M. \& Hughes, C. (1998). A swarmingdefective mutant of Proteus mirabilis lacking a putative cationtransporting membrane P-type ATPase. Microbiology 144, 1957-1961.

Liaw, S. J., Lai, H. C., Ho, S. W., Luh, K. T. \& Wang, W. B. (2000). Inhibition of virulence factor expression and swarming differentiation in Proteus mirabilis by p-nitrophenylglycerol. J Med Microbiol 49, 725-731.

Liaw, S. J., Lai, H. C., Ho, S. W., Luh, K. T. \& Wang, W. B. (2001). Characterisation of $p$-nitrophenylglycerol-resistant Proteus mirabilis super-swarming mutants. J Med Microbiol 50, 1039-1048.

Liaw, S. J., Lai, H. C. \& Wang, W. B. (2004). Modulation of swarming and virulence by fatty acids through the RsbA protein in Proteus mirabilis. Infect Immun 72, 6836-6845.

Mahady, G. B. \& Pendland, S. L. (2000). Resveratrol inhibits the growth of Helicobacter pylori in vitro. Am J Gastroenterol 95, 1849.

Mobley, H. L. \& Warren, J. W. (1987). Urease-positive bacteriuria and obstruction of long-term urinary catheters. J Clin Microbiol 25, 2216-2217.

Mobley, H. L. \& Hausinger, R. P. (1989). Microbial ureases: significance, regulation, and molecular characterization. Microbiol Rev 53, 85-108.

Mobley, H. L., Chippendale, G. R., Swihart, K. G. \& Welch, R. A. (1991). Cytotoxicity of the HpmA hemolysin and urease of Proteus mirabilis and Proteus vulgaris against cultured human renal proximal tubular epithelial cells. Infect Immun 59, 2036-2042.

Nachin, L., Nannmark, U. \& Nystrom, T. (2005). Differential roles of the universal stress proteins of Escherichia coli in oxidative stress resistance, adhesion and motility. J Bacteriol 187, 6265-6272. 
Nealson, K. \& Hastings, J. (1991). The Luminous Bacteria, 2nd edn. New York: Springer.

Ochsendorf, F. R. (1999). Infections in the male genital tract and reactive oxygen species. Hum Reprod Update 5, 399-420.

Peerbooms, P. G., Verweij, A. M. \& MacLaren, D. M. (1984). Vero cell invasiveness of Proteus mirabilis. Infect Immun 43, 1068-1071.

Rather, P. N. (2005). Swarmer cell differentiation in Proteus mirabilis. Environ Microbiol 7, 1065-1073.

Rauprich, O., Matsushita, M., Weijer, C. J., Siegert, F., Esipov, S. E. \& Shapiro, J. A. (1996). Periodic phenomena in Proteus mirabilis swarm colony development. J Bacteriol 178, 6525-6538.

Schneider, R., Lockatell, C. V., Johnson, D. \& Belas, R. (2002). Detection and mutation of a luxS-encoded autoinducer in Proteus mirabilis. Microbiology 148, 773-782.

Sturgill, G. \& Rather, P. N. (2004). Evidence that putrescine acts as an extracellular signal required for swarming in Proteus mirabilis. Mol Microbiol 51, 437-446.

Takeda, S., Fujisawa, Y., Matsubara, M., Aiba, H. \& Mizuno, T. (2001). A novel feature of the multistep phosphorelay in Escherichia coli: a revised model of the $\mathrm{RcsC} \rightarrow \mathrm{YojN} \rightarrow \mathrm{RcsB}$ signalling pathway implicated in capsular synthesis and swarming behaviour. Mol Microbiol 40, 440-450.

Tang, Y., Guest, J. R., Artymiuk, P. J., Read, R. C. \& Green, J. (2004). Post-transcriptional regulation of bacterial motility by aconitase proteins. Mol Microbiol 51, 1817-1826.

Tegos, G., Stermitz, F. R., Lomovskaya, O. \& Lewis, K. (2002). Multidrug pump inhibitors uncover remarkable activity of plant antimicrobials. Antimicrob Agents Chemother 46, 3133-3141.

Teplitski, M., Robinson, J. B. \& Bauer, W. D. (2000). Plants secrete substances that mimic bacterial $\mathrm{N}$-acyl homoserine lactone signal activities and affect population density-dependent behaviors in associated bacteria. Mol Plant Microbe Interact 13, 637-648.

Warren, J. W., Tenney, J. H., Hoopes, J. M., Muncie, H. L. \& Anthony, W. C. (1982). A prospective microbiologic study of bacteriuria in patients with chronic indwelling urethral catheters. J Infect Dis 146, 719-723.

Zhang, L. H. (2003). Quorum quenching and proactive host defense. Trends Plant Sci 8, 238-244. 